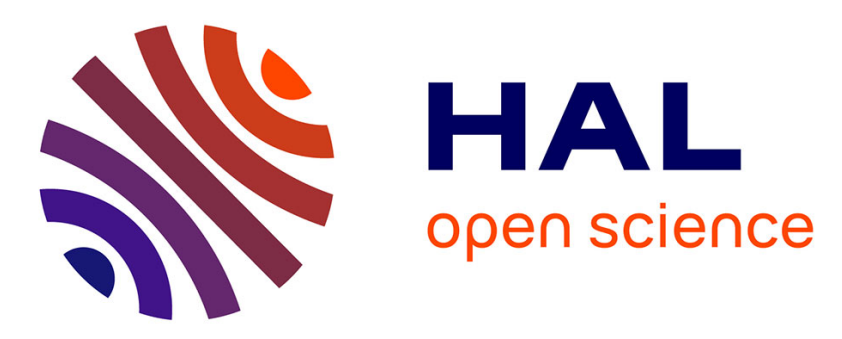

\title{
One-pot asymmetric cyclocarbohydroxylation sequence for the enantioselective synthesis of functionalised cyclopentanes
}

Wilfried Raimondi, Grégory Lettieri, Jean-Pierre Dulcère, Damien Bonne, Jean Rodriguez

\section{To cite this version:}

Wilfried Raimondi, Grégory Lettieri, Jean-Pierre Dulcère, Damien Bonne, Jean Rodriguez. Onepot asymmetric cyclocarbohydroxylation sequence for the enantioselective synthesis of functionalised cyclopentanes. Chemical Communications, 2010, 46, pp.7247-7249. 10.1039/c0cc01940b . hal00677033

\section{HAL Id: hal-00677033 \\ https://hal.science/hal-00677033}

Submitted on 7 Mar 2012

HAL is a multi-disciplinary open access archive for the deposit and dissemination of scientific research documents, whether they are published or not. The documents may come from teaching and research institutions in France or abroad, or from public or private research centers.
L'archive ouverte pluridisciplinaire HAL, est destinée au dépôt et à la diffusion de documents scientifiques de niveau recherche, publiés ou non, émanant des établissements d'enseignement et de recherche français ou étrangers, des laboratoires publics ou privés. 


\title{
One-pot asymmetric cyclocarbohydroxylation sequence for the enantioselective synthesis of functionalised cyclopentanes $\dagger$
}

\author{
Wilfried Raimondi, Grégory Lettieri, Jean-Pierre Dulcère, Damien Bonne* and \\ Jean Rodriguez*
}

Received 17th June 2010, Accepted 26th July 2010

DOI: $10.1039 / \mathrm{c0cc01940b}$

A new method has been developed for the enantioselective synthesis of highly functionalised cyclopentanes bearing up to three stereogenic centres with very high stereoselectivity. This one-pot process combines an enantioselective organocatalytic Michael addition with a highly diastereoselective $[3+2]-$ cycloaddition-fragmentation step.

The development of organocatalytic enantioselective methods to access enantiopure molecules has received much attention in the last ten years due to the many advantages in terms of efficiency, selectivity and environmental benefits offered by organocatalysis. ${ }^{1}$ When the method involves simple starting materials and is associated with one-pot multiple bond-forming transformations (MBFTs), ${ }^{2}$ the resulting tools are particularly useful for reaching a high level of structural complexity and functional diversity.

In this context, the asymmetric organocatalysed Michael addition of various nucleophiles to nitroolefins represents a very useful reaction. ${ }^{3}$ Although malonates have been used most often in Michael addition, ${ }^{4}$ synthetic developments in a sequential way, by further modification of the adducts, are limited by the lack of reactivity of 2-substituted malonates. An interesting recent example concerns the functional group pairing of modular nitro scaffolds obtained from enantioselective Michael addition catalysed by Cinchona alkaloids. ${ }^{5}$

Given our interest in the reactivity of nitroalkenes ${ }^{6}$ and domino processes, ${ }^{7}$ we envisioned a one-pot consecutive transformation consisting of an enantioselective organocatalytic Michael addition between nitroalkenes $\mathbf{1}$ and 2-allylmalonates 2 followed by an in situ [3+2] nitronate cycloadditionfragmentation sequence leading to highly functionalised cyclopentanone oximes 4 (Scheme 1). The resulting intramolecular carbohydroxylation of the non-activated double bond with formation of the oxime function has been rarely exploited to date $^{8}$ and this would constitute the first example of an enantioselective version. Herein, we disclose our results on this one-pot consecutive cyclopentannelation with a remote hydroxylation leading to highly functionalised five-membered rings with concomitant creation of two $\mathrm{C}-\mathrm{C}$ bonds, one

UMR CNRS 6263 iSm2, Aix-Marseille Université,

Centre Saint Jérôme, service 531, 13397 Marseille Cedex 20, France.

E-mail: jean.rodriguez@univ-cezanne.fr,

damien.bonne@univ-cezanne.fr; Fax: (+33) 491289 187;

Tel: $(+33) 491289187$

$\dagger$ Electronic supplementary information (ESI) available: Complete experimental procedures and characterisation of all compounds. CCDC 764561. For ESI and crystallographic data in CIF or other electronic format see DOI: $10.1039 / \mathrm{c} 0 \mathrm{cc} 01940 \mathrm{~b}$

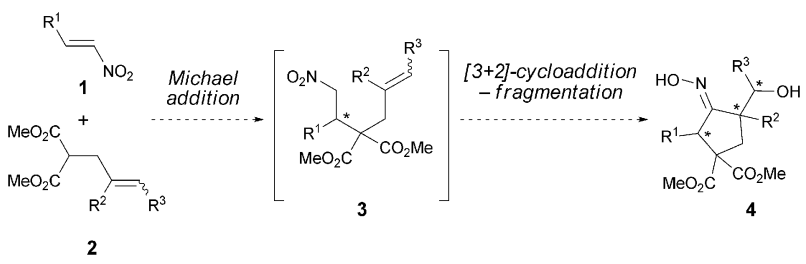

Scheme 1 Strategy for the one-pot stereoselective construction of functionalised cyclopentanes.

$\mathrm{C}-\mathrm{O}$ bond and the control of up to three stereogenic centres with very high diastereo- and enantioselectivites. 9,10

We first started to investigate the organocatalytic Michael addition and catalysts $\mathbf{I},{ }^{11} \mathbf{I I}^{12}$ and $\mathbf{I I I}{ }^{4 b}$ were screened under standard conditions (Table 1). Catalysts I and III bearing two different hydrogen bond donor sites respectively, in toluene or THF, were the most efficient (entries 1 and 4) although I showed a reduced activity in THF (entry 2). Catalyst II in toluene, showed a good selectivity but slightly lower yield (entry 3). Finally, when catalyst III was used in toluene instead of THF, we observed a significant decrease in the yield which could be due to its lower solubility (entry 5). We were also very pleased to find that both enantiomers of $\mathbf{3 a}$ could be obtained using structurally different catalysts I and III.

Table 1 Screening of reaction conditions for the enantioselective Michael addition of dimethyl 2-allylmalonate (2a) to $\beta$-nitrostryrene (1a) ${ }^{a}$
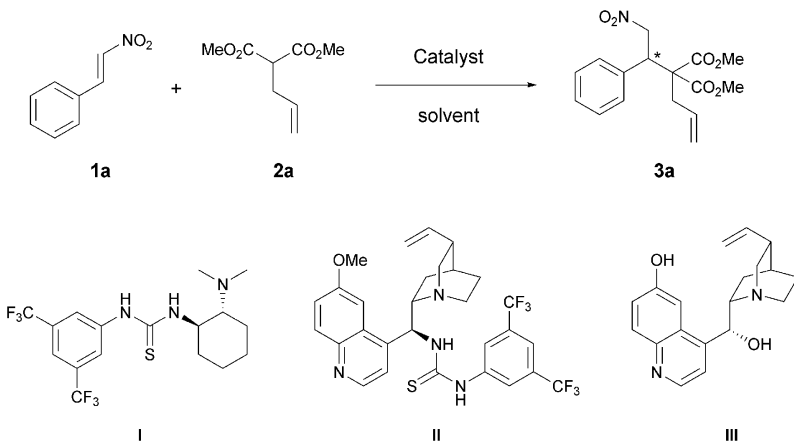

\begin{tabular}{lllll}
\hline \multicolumn{1}{c}{ I } & \multicolumn{2}{c}{ III } \\
\hline Entry & Catalyst & Solvent & Yield $(\%)^{b}$ & Ee $(\%)^{c}$ \\
\hline 1 & I & Toluene & 95 & $92(S)$ \\
2 & I & THF & $95^{d}$ & $88(S)$ \\
3 & II & Toluene & 78 & $90(R)$ \\
4 & III & THF & 94 & $90(R)$ \\
5 & III & Toluene & 67 & $87(R)$
\end{tabular}

${ }^{a}$ Reaction conditions: $1 \mathrm{mmol}$ of $\mathbf{1 a}, 2 \mathrm{mmol}$ of $\mathbf{2 a}$ and catalyst I, II or III $(10 \mathrm{~mol} \%)$ in $2 \mathrm{~mL}$ of solvent at room temperature for 48 h. ${ }^{b}$ Isolated yield by flash chromatography. ${ }^{c}$ Determined by HPLC on a chiral stationary phase. ${ }^{d} 7$ days of reaction time. 


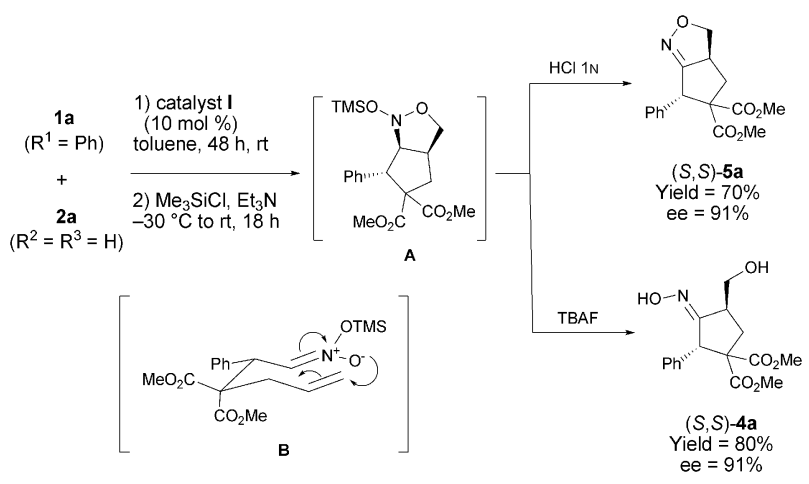

Scheme 2 Cyclocarbohydroxylation sequence.

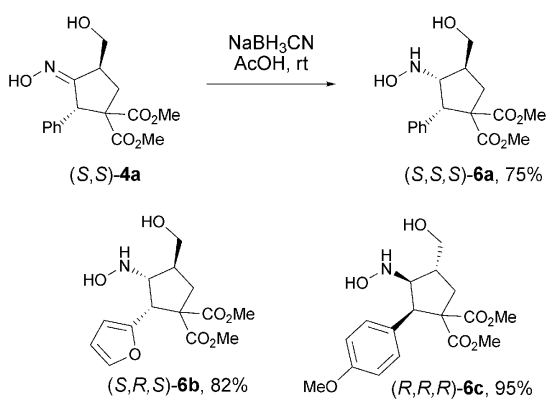

Scheme 3 Diastereoselective reduction of oximes.

We next turned our attention to the carbohydroxylation via an intramolecular [3+2]-silylnitronate olefin cyclisation (ISOC)-fragmentation sequence (Scheme 2). ${ }^{13}$ In the first attempt, generation of the silylnitronate resulted in a highly stereoselective process driven by a 1,3-allylic strain ${ }^{6,14}$ with a total transfer of chirality to furnish the transient isoxazolidine A through the preferred nitronate conformation B. Treatment with aqueous $\mathrm{HCl}$ did not result in its fragmentation but led to the known isoxazoline 5a with 70\% yield in diastereomerically pure form. ${ }^{15}$ More interestingly, using tetrabutylammonium fluoride (TBAF) provoked the expected selective fragmentation affording the corresponding hydroxymethyl oxime $\mathbf{4 a}$ also in a highly stereoselective manner ${ }^{16}$ probably through the tautomeric nitroso intermediate. ${ }^{13 g}$ The absolute configuration was unambiguously determined to be $(E)-(2 S, 4 S)$ by X-ray crystallographic analysis of $\mathbf{4 a}+\dagger$

The overall cyclocarbohydroxylation in a one-pot consecutive manner with organocatalysts I and III has been extended to various substrates (Table 2). Pleasingly, in all cases, this led to the formation of the desired cyclopentanone oximes $4 \mathbf{a}-\mathbf{n}$ in good to excellent yields and with high diastereoand enantioselectivities. ${ }^{17}$ This allowed the one-pot creation of a five-membered ring and the control of two stereogenic centres starting from commercially available acyclic achiral substrates and operated a remote hydroxylation. The use of catalysts I and III allowed the formation of both enantiomers with comparable efficiencies (entries 1, 2 and 13, 14). Aromatic nitroalkenes bearing electron-withdrawing and electrondonating groups reacted well in the reaction and gave all excellent enantioselectivities (entries 3-8). However 4h was obtained in moderate yield (entry 9, 57\%) due to the lower electrophilic character of the corresponding electron rich nitroalkene $\mathbf{1 h}$. Heteroaromatic nitroolefins proved also to be very good substrates affording the desired products $\mathbf{4 i - 1}$ (entries 10-13) in good yields (72-95\%) and excellent enantioselectivities $(93-97 \%)$. The $(R, S)$-enantiomer of 41 was also easily obtained using catalyst $\mathbf{I}$, although with a somewhat

Table 2 Scope of the enantioselective cyclocarbohydroxylation sequence ${ }^{a}$

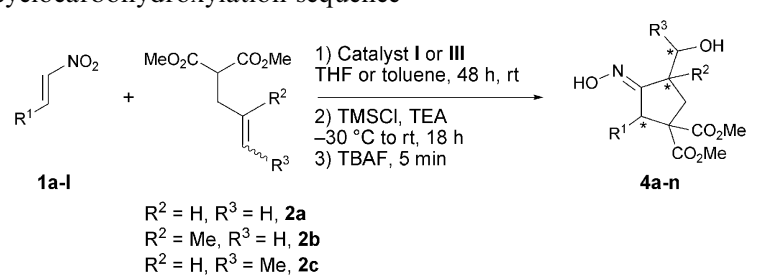

\begin{tabular}{|c|c|c|c|c|c|c|}
\hline Entry & $\mathrm{R}^{1}$ & Malonate 2 & Catalyst & Product & Yield $(\%)^{b}$ & $\operatorname{Ee}(\%)^{c}$ \\
\hline 1 & $\mathrm{Ph}(\mathbf{1 a})$ & $2 \mathbf{a}$ & III & $(R, R)-\mathbf{4 a}$ & 92 & 91 \\
\hline 2 & $\mathrm{Ph}(\mathbf{1 a})$ & 2a & I & $(S, S)-\mathbf{4 a}$ & 74 & 97 \\
\hline 3 & $4-\mathrm{FC}_{6} \mathrm{H}_{4}(\mathbf{1 b})$ & $2 \mathbf{a}$ & III & $(R, R)-\mathbf{4 b}$ & 81 & 93 \\
\hline 4 & $4-\mathrm{MeOC}_{6} \mathrm{H}_{4}(\mathbf{1 c})$ & $2 \mathbf{a}$ & III & $(R, R)-\mathbf{4 c}$ & 73 & 97 \\
\hline 5 & $2-\mathrm{BrC}_{6} \mathrm{H}_{4}(\mathbf{1 d})$ & $2 \mathbf{a}$ & I & $(R, S)-\mathbf{4 d}$ & 80 & 93 \\
\hline 6 & $4-\mathrm{MeC}_{6} \mathrm{H}_{4}(\mathbf{1 e})$ & $\mathbf{2 a}$ & III & $(R, R)-4 \mathbf{e}$ & 99 & 88 \\
\hline 7 & $2-\mathrm{Cl}-6-\mathrm{FC}_{6} \mathrm{H}_{4}(\mathbf{1 f})$ & 2a & III & $(S, R)-\mathbf{4 f}$ & 97 & 92 \\
\hline 8 & $2-\mathrm{NO}_{2} \mathrm{C}_{6} \mathrm{H}_{4}(\mathbf{1 g})$ & 2a & III & $(R, R)-\mathbf{4 g}$ & 82 & 98 \\
\hline 9 & $3,4,5-(\mathrm{MeO}){ }_{3} \mathrm{C}_{6} \mathrm{H}_{4}(\mathbf{1 h})$ & $2 \mathbf{a}$ & III & $(R, R)-\mathbf{4 h}$ & 57 & 94 \\
\hline 10 & 2-Furyl (1i) & $2 \mathbf{a}$ & III & $(R, R)-\mathbf{4 i}$ & 95 & 93 \\
\hline 11 & 3-Furyl (1j) & $2 \mathbf{a}$ & III & $(R, R)-\mathbf{4 j}$ & 80 & 96 \\
\hline 12 & 2-Thienyl (1k) & $\mathbf{2 a}$ & III & $(R, R)-\mathbf{4 k}$ & 77 & 97 \\
\hline 13 & 2-Pyridinyl (11) & 2a & III & $(S, R)-\mathbf{4 I}$ & 72 & 95 \\
\hline 14 & 2-Pyridinyl (11) & $2 \mathbf{a}$ & I & $(R, S)-\mathbf{4} \mathbf{I}$ & 71 & 89 \\
\hline 15 & $\mathrm{Ph}(\mathbf{1 a})$ & 2b & III & $(R, R)-\mathbf{4 m}$ & 60 & 92 \\
\hline 16 & $\mathrm{Ph}(\mathbf{1 a})$ & $(E)-\mathbf{2 c}$ & III & $(R, R, S)-\mathbf{4 n}$ & 84 & 91 \\
\hline 17 & $\mathrm{Ph}(\mathbf{1 a})$ & $(Z)-\mathbf{2 c}$ & III & $(R, R, R)-\mathbf{4 n}$ & 74 & 94 \\
\hline
\end{tabular}

${ }^{a}$ Reaction conditions: $1 \mathrm{mmol}$ of $\mathbf{1}, 2 \mathrm{mmol}$ of $\mathbf{2}$ catalyst in $2 \mathrm{~mL}$ of solvent (toluene with I, THF with III). ${ }^{b}$ Isolated yield by flash chromatography. ${ }^{c}$ Determined by HPLC on a chiral stationary phase. 
reduced efficiency (entry 14). When dimethyl 2-methallylmalmate (2b) was employed, the consecutive process allowed the formation and control of an all-carbon quaternary stereogenic centre ${ }^{18}$ in the final product $\mathbf{4 m}$ with $92 \%$ ee (entry 15 ). Finally, when $(E)$-2c was used as the starting malonate, the consecutive reaction sequence afforded the cyclopentanone oxime $4 \mathbf{n}$ with the stereospecific control of a third stereogenic centre in high yield and selectivity (entry 16). Starting from $(Z)$-2c gave the single diastereomer of $\mathbf{4 n}$ with opposite configuration of the carbon bearing the hydroxy function (entry 17).

Oximes are an important class of compounds with potential pharmaceutical properties ${ }^{19}$ and constitute versatile building blocks since they can be easily transformed into various functional groups. ${ }^{20}$ As an illustration of their synthetic potential, oximes $\mathbf{4 a}, \mathbf{4} \mathbf{c}$ and $\mathbf{4 i}$ were reduced with $\mathrm{NaBH}_{3} \mathrm{CN}$ affording the corresponding hydroxylamines $\mathbf{6 a}, \mathbf{6 b}$ and $\mathbf{6 c}$ as single diastereomers in good yields where a supplementary stereogenic centre was created (Scheme 3). Here again, depending on the catalyst used in the consecutive enantioselective reaction, both configurations of the new created stereogenic centre can be accessed.

In conclusion, we have identified two structurally different and complementary organocatalysts for the successful enantiodivergent cyclocarbohydroxylation sequence allowing the construction of highly functionalised and optically pure functionalised cyclopentanes with the creation and control of up to three stereogenic centres. The high efficiency and the practical simplicity of the method make it an important platform for the stereoselective formation of complex molecules.

This research was supported by the Universite Paul Cézanne and the CNRS (iSm2 - UMR 6263). W.R. thanks the Ministère de l'Enseignement Supérieur et de la Recherche for a doctoral fellowship. We thank Dr N. Vanthuyne (iSm2 - UMR 6263) for chiral HPLC analysis and M. Giorgi (www.spectropole.fr) for $\mathrm{X}$-ray structure.

\section{Notes and references}

1 For recent reviews on organocatalysis, see: (a) S. Bertelsen and K. A. Jørgensen, Chem. Soc. Rev., 2009, 38, 2178-2189; (b) A. Dondoni and A. Massi, Angew. Chem., Int. Ed., 2008, 47, 4638-4660; (c) C. F. Barbas III, Angew. Chem., Int. Ed., 2008, 47, 42-47; (d) P. Melchiorre, M. Marigo, A. Carlone and G. Bartoli, Angew. Chem., Int. Ed., 2008, 47, 6138-6171; (e) D. W. C. MacMillan, Nature, 2008, 455, 304-308; (f) Special issue on asymmetric organocatalysis Chem. Rev., 2007, 107, 5413; (g) Enantioselective Organocatalysis, ed. P. I. Dalko, Wiley-VCH, Weinheim, 2007; (h) Asymmetric Organocatalysis: From Biomimetic Concepts to Applications in Asymmetric Synthesis, ed. A. Berkessel, H. Groger and D. W. C. MacMillan, Wiley-VCH, Weinheim, 2005.

2 Y. Coquerel, T. Boddaert, M. Presset, D. Mailhol and J. Rodriguez, in Ideas in Chemistry and Molecular Sciences: Advances in Synthetic Chemistry, ed. B. Pignataro, Wiley-VCH, Weinheim, 2010, and references therein.

3 For reviews on asymmetric organocatalysed conjugate additions, see: (a) C. Palomo, M. Oiarbide and R. López, Chem. Soc. Rev., 2009, 38, 632-653; (b) S. B. Tsogoeva, Eur. J. Org. Chem., 2007, 1701-1716; (c) S. Sulzer-Mossé and A. Alexakis, Chem. Commun., 2007, 3123-3135; (d) J. L. Vicario, D. Badía and L. Carrillo, Synthesis, 2007, 2065-2092; (e) D. Almasi, D. A. Alonso and C. Nájera, Tetrahedron: Asymmetry, 2007, 18, 299-365.
4 For selected exemples of organocatalytic enantioselective addition of malonates on nitroolefins, see: (a) T. Okino, Y. Hoashi, T. Furukawa, X. Xu and Y. Takemoto, J. Am. Chem. Soc., 2005, 127, 119-125; (b) H. Li, Y. Wang, L. Tang and L. Deng, J. Am. Chem. Soc., 2004, 126, 9906-9907; (c) H. Li, Y. Wang, L. Tang, F. Wu, X. Liu, C. Guo, B. M. Foxman and L. Deng, Angew. Chem., Int. Ed., 2006, 44, 105-108; (d) S. H. McCooey and S. J. Connon, Angew. Chem., Int. Ed., 2005, 44, 6367-6370; (e) J. Ye, D. J. Dixon and P. S. Hynes, Chem. Commun., 2005, 4481-4483; (f) M. Terada, H. Ube and Y. Yaguchi, J. Am. Chem. Soc., 2006, 128, 1454-1455.

5 E. Comer, E. Rohan, L. Deng and J. A. Porco, Jr., Org. Lett., 2007, 9, 2123-2126.

6 E. Dumez, A.-C. Durand, M. Guillaume, P.-Y. Roger, R. Faure, J.-M. Pons, G. Herbette, J.-P. Dulcère, D. Bonne and J. Rodriguez, Chem.-Eur. J., 2009, 15, 12470-12488.

7 For recent examples, see: (a) M. Presset, Y. Coquerel and J. Rodriguez, Org. Lett., 2009, 11, 5706-5709; (b) C. Allais, T. Constantieux and J. Rodriguez, Chem.-Eur. J., 2009, 15, 12945-12948.

8 For a diastereoselective intramolecular carbohydroxylation reaction, see: A. V. Stepanov and V. V. Veselovsky, Russ. Chem. Bull., 2002, 51, 359-361.

9 For selected examples of enantioselective organocatalysed construction of cyclopentanes, see: (a) D. Enders, C. Wang and J. W. Bats, Angew. Chem., Int. Ed., 2008, 47, 7539-7542; (b) B. Tan, P. J. Chua, X. Zeng, M. Lu and G. Zhong, Org. Lett., 2008, 10, 3489-3492; (c) V. Nair, B. P. Babu, S. Vellalath, V. Varghese, A. E. Raveendran and E. Sures, Org. Lett., 2009, 11, 2507-2510.

10 We previously described a three-step sequence affording fusedisoxazolines from aldehydes and nitroalkenes: D. Bonne, L. Salat, J.-P. Dulcère and J. Rodriguez, Org. Lett., 2008, 10, $5409-5412$.

11 (a) T. Okino, Y. Hoashi and Y. Takemoto, J. Am. Chem. Soc., 2003, 125, 12672-12673; (b) A. Berkessel and B. Seelig, Synthesis, $2009,12,2113-2115$.

12 (a) B. Vakulya, S. Varga, A. Csámpai and T. Soós, Org. Lett., 2005, 7, 1967-1970; (b) B. Vakulya, S. Varga and T. Soós, J. Org. Chem., 2008, 73, 3475-3480.

13 (a) I. N. N. Namboothiri, A. Hassner and H. E. Gottlieb, J. Org. Chem., 1997, 62, 485-492; (b) A. Hassner, O. Friedman and W. Dehaen, Liebigs Ann./Recl., 1997, 587-594; (c) S. Ghorai, R. Mukhopadhyay, A. P. Kundu and A. Bhattacharjya, Tetrahedron, 2005, 61, 2999-3012; (d) J. L. Duffy and M. J. Kurth, J. Org. Chem., 1994, 59, 3783-3785; (e) T. Ishikawa, Y. Shimizu, T. Kudoh and S. Saito, Org. Lett., 2003, 5, 3879-3882; (f) T. Kudoh, T. Ishikawa, Y. Shimizu and S. Saito, Org. Lett., 2003, 5, 3875-3878; (g) P.-Y. Roger, A.-C. Durand, J. Rodriguez and J.-P. Dulcère, Org. Lett., 2004, 6, 2027-2029.

14 R. W. Hoffmann, Chem. Rev., 1989, 89, 1841-1860.

15 Only one diastereomer can be detected in proton NMR spectra. For one isolated example of a related two-step Michael addition-nitrile oxide cycloaddition leading to $\mathbf{5 a}$ with very low diastereoselectivity, see ref. 5 .

16 Phenyl and $\mathrm{CH}_{2} \mathrm{OH}$ substituents in 4 a were exclusively trans. Besides, the oxime $4 a$ was isolated as a $96: 4 \mathrm{E} / \mathrm{Z}$ ratio.

17 When 2-alkyl-substituted nitroalkenes were used as substrates, only traces of products were formed. This non reactivity of alkylnitroolefins with malonates has already been observed: Y.-N. Xuan, S.-Z. Nie, L.-T. Dong, J.-M. Zhang and M. Yan, Org. Lett., 2009, 11, 1583-1586.

18 (a) M. Bella and T. Gasperi, Synthesis, 2009, 1583-1614; (b) C. J. Douglas and L. E. Overman, Proc. Natl. Acad. Sci. U. S. A., 2004, 101, 5363-5367.

19 (a) Y. Ashani and I. Silman, The Chemistry of Hydroxylamines, Oximes and Hydroxamic Acids, ed. Z. Rappoport and J. F. Liebman, WILEY, New York, 2008, p. 609; (b) H. P. M. van Helden, R. W. Busker, B. P. C. Melchers and P. L. B. Bruijnzeel, Arch. Toxicol., 1996, 70, 779-786.

20 For a review, see: J. P. Adams, J. Chem. Soc., Perkin Trans. 1, 2000, 125-139. 